\title{
Health and wellness centers: a paradigm shift in health care system of India?
}

\author{
Hariom K. Solanki ${ }^{1}$, Rama Shankar Rath ${ }^{2}$, Vijay Silan ${ }^{3}$, Satya V. Singh ${ }^{1}$
}

\begin{abstract}
${ }^{1}$ Department of Community Medicine, Dr. Baba Saheb Ambedkar Medical College, Rohini, Delhi, India
${ }^{2}$ Department of Community Medicine and Family Medicine, All India Institute of Medical Sciences, Gorakhpur, Uttar Pradesh, India

${ }^{3}$ Department of Community Medicine, BPS Government Medical College for Women, Khanpur Kalan, Sonepat, Haryana, India
\end{abstract}

Received: 15 November 2019

Revised: 07 January 2020

Accepted: 08 January 2020

\section{*Correspondence:}

Dr. Rama Shankar Rath,

E-mail: ramashankar.aiims@gmail.com

Copyright: ( ) the author(s), publisher and licensee Medip Academy. This is an open-access article distributed under the terms of the Creative Commons Attribution Non-Commercial License, which permits unrestricted non-commercial use, distribution, and reproduction in any medium, provided the original work is properly cited.

\section{ABSTRACT}

An ambitious attempt to achieve the goal of universal 'comprehensive' primary care through health and wellness centres under the Ayushmann Bharat Scheme (ABS) has been made by the Ministry of Health and Family Welfare, Government of India. The scheme has widened the package of services available to beneficiaries and it also envisages continuum of care. However, there are pre-existing weaknesses in the three tired public health system in India which may threaten the success of this scheme. In this article we describe and analyze the newer services or initiatives at the health and wellness centres under the ABS. We also attempt to identify the Strengths, weaknesses, threats and opportunities associated with this initiative.

Keywords: Comprehensive primary health care, Universal health coverage, Ayushmann Bharat Scheme, Health systems

\section{INTRODUCTION}

With economic development and changing lifestyles the disease epidemiology in India is changing. Noncommunicable diseases (NCDs), mental health issues and accidents and injuries are emerging as major new health threats for people residing in India. ${ }^{1}$ Existing weaknesses in the three-tiered public health system has meant that the coverage is not uniform, existing health facilities are overburdened and people have to look for alternate providers - incurring huge out of pocket expenditure (OoPE); pushing many into poverty. ${ }^{2,3}$ In India, Universal Health Coverage (UHC) through increasing access, improving quality and lowering the cost of health care services is the stated goal of National Health Policy $2017 .^{4}$
There is wide consensus that the primary health care model is most appropriate to achieve UHC. Alma-Ata declaration in 1978 followed by Astana declaration in 2008 have emphasized on the importance of primary health care in achievement of UHC. ${ }^{5}$ The relevant domains that must be addressed by any UHC initiative to be meaningful include the package of services to be provided, population to be covered and the cost of such a package to the community and the country. With the purpose of providing improved service coverage and financial protection, Ministry of Health and Family Welfare, Govt. of India in 2018 introduced Prime Minister Jan Aarogya Yojana (PM-JAY) also known as Ayushmann Bharat Scheme (ABS) which comprises a 'comprehensive' primary health care model operational at the community level through health and wellness centres 
(HWCs) to achieve maximum population coverage and a publicly funded third party insurance system to reduce the OoPE on the in-patient secondary and selected tertiary care services. $^{6-8}$

\section{Objective}

The objective of this article is to analyze the strengths, weaknesses, opportunities and threats to the newly introduced 'comprehensive' primary care model through the health and wellness centers (HWCs) under PM-JAY.

\section{EXISTING PRIMARY HEALTH CARE SYSTEM}

The existing primary health care system for rural population is a hub and spoke model where at the periphery sub-health centres (SHCs) covering a population of about 5000 (3000 in difficult terrains or sparsely populated areas) act as spoke and primary health centres (PHCs) acting as nodes for about six sub-health centres and catering to a population of $30,000(20,000$ in difficult terrains or sparsely populated areas)..${ }^{9,10}$ At the centre in this model acting as hub, exists the District Hospital which provides both primary and secondary care but is predominantly meant to deliver secondary care. In between there are other nodes like community health centres (typically at 100,000 to 120,000 population) and sub-district hospitals which predominantly cater to maternal and child health care needs. ${ }^{11,12}$

\section{GAPS OR WEAKNESS IN THE EXISTING PHC SYSTEM}

In the existing primary health care model, the following problems are perceived.

\section{Lack of population enumeration or beneficiary mapping data}

Population enumeration is an important aspect of any effective health care delivery system. It allows health care providers to become familiar with the population and helps in assessment of the health services requirement of the community for better planning of service delivery and logistics management. In the existing scheme of things although there is provision of population enumeration, however, maintenance of such updated records at the SHCs is doubtful. Thus, health care providers often remain clueless about the expected beneficiaries when planning for health interventions (only family welfare services beneficiary data can be considered an exception). This lack of data affects many key interventions including routine immunization and more specifically when mass population-based activities like pulse polio campaign or Mission Indradhanush campaign are planned or implemented.

\section{Narrow range of services}

SHCs has been working more on maternal and child health since long. However, National Rural Health
Mission (NRHM) made it more obvious. It leaves a wide range of health issues pertaining to NCDs, mental health issues etc. under addressed or unaddressed. ${ }^{8}$

\section{Lack of defined referral mechanisms}

At present, referral from lower centers i.e. SHC and PHC to the higher centers neither have definite pathway nor a defined process. This situation has resulted in higher waiting period at referral facility, poor patient satisfaction with the public health system as a whole and thus leads to poor public service utilization by the people who need it most. ${ }^{13,14}$ Although NRHM has contributed to health of the community however referals are still unmanagable.

\section{Continuity of services}

There is no continuity of services along the public health facilities as a person is referred from one health facility to another. For example, there is almost total duplication starting from registration to investigations before a treatment plan is finalized for a patient who has been referred from another facility. Also, the provision of follow up services to patient seen and managed at higher centers when they no longer require specialist care for follow up is lacking.

\section{Health promotion and diseases prevention services/activities}

With an honorable exception of immunization other health promotion or disease prevention activities are done only for namesake at most places. There is little or no emphasis on health promotion and disease prevention especially when NCDs, mental illnesses or injuries and accidents are concerned.

\section{CONCEPT AND OPERATIONALIZATION OF HWCS}

HWCs are the new proposed facility for providing 'comprehensive' primary health care at the grass root level. Selected PHCs and most SHCs will be converted to HWCs (i.e. HWC-PHC and HWC-SHC respectively) with extended package of services catering to the promotive, preventive and curative health care needs of the population. The list of twelve domains under which health services will be provided HWCs is given in the Table 1.6

HWCs will be operationalized with in the overall structure of existing health care system. Provision of one Community Health Officer (CHO) at each HWC-SHC has been made. CHOs are either Nursing graduates or have a bachelor's degree in traditional Indian system of medicine (Ayurveda) and have to undergo a six-month certificate program to get appointment as CHO. ${ }^{6}$ They are responsible for provision the health care services to the population under the HWC-SHC and reporting to the PHC in-charge. This would be done with the help of preexisting staff at the SHC. 
Table 1: Basic service domains of HWCs.

Service domains

1. Care during pregnancy and child birth

2. Neonatal and infant health care services

3. Childhood and adolescent health care services

4. Family planning, contraceptive services and other reproductive health services

5. Management of communicable diseases including national health programmes

6. Management of common communicable diseases and outpatient care for acute simple illness and minor ailments

7. Screening, prevention, control and management of NCDs

8. Care of common ophthalmic and ENT problems

9. Basic oral health care

10. Elderly and palliative care

11. Emergency medical services

12. Screening and basic management of mental health problems

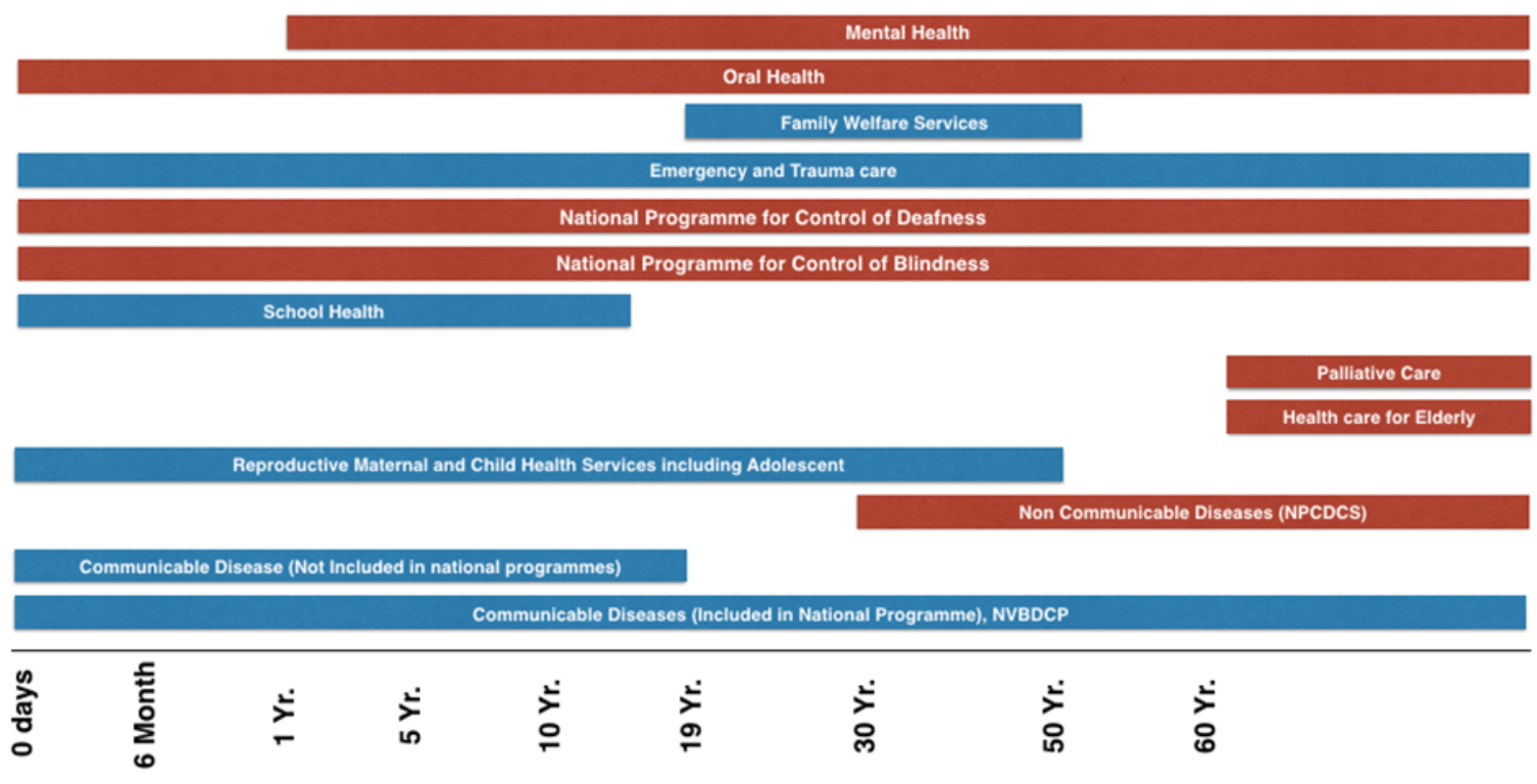

Figure 1: Services proposed at the HWCs and the beneficiary age groups.

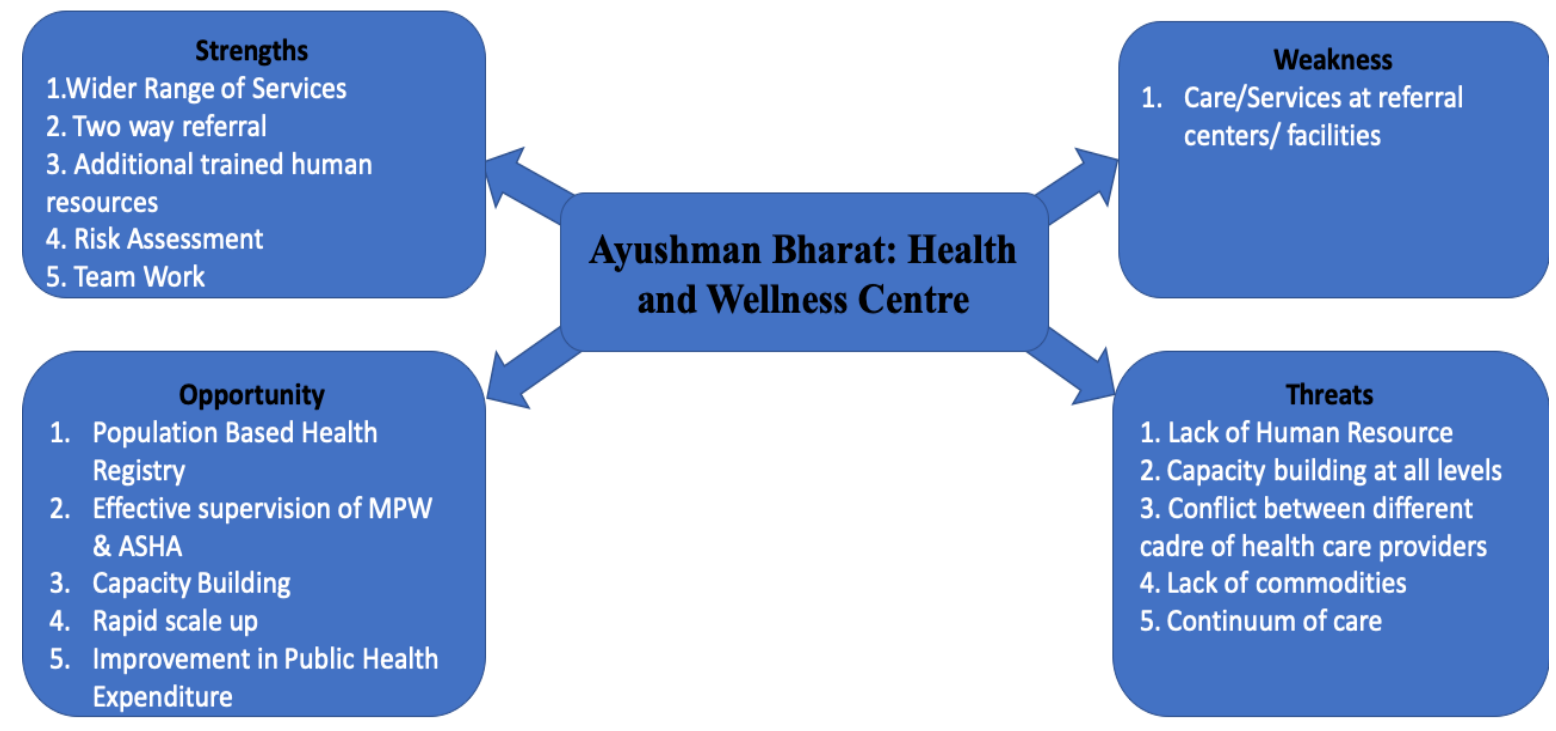

Figure 2: Summary of SWOT analysis of HWCs. 


\section{NEWER INITIATIVES UNDER HWCS}

\section{Comprehensive PHC}

Newly proposed HWCs are supposed to provide comprehensive primary health care under 12 service domains as listed in Table 1. This will include all aspects - promotive, preventive and curative - of the health care. ${ }^{6}$

\section{Risk assessment for selected common health conditions:}

To assess the risk profile of the community members for the selected NCDs; population enumeration and risk assessment will be done for NCDs related common risk factors. Provision for risk assessment of environmental exposure, selected mental and chronic respiratory conditions has also been made. ${ }^{6}$

\section{Screening for NCDs and cancers}

Screening for hypertension (HTN), diabetes mellitus $(\mathrm{DM})$, oral cancer, breast cancer and cervical cancer has been stipulated on periodic basis at the HWC-SHC. Though HTN and DM screening was supposed to be done even earlier but little is known about the outcome of these screening activities. ${ }^{6,15}$

\section{Continuum of care}

Central theme of HWCs is provision of Continuum of Care i.e. care of the patient starting from their home to the primary facility to the referral facility till the person is back at home again where follow up care will be provided. This forms the underlying basis of people centric approach envisaged in the PMJAY or ABS. The referred cases from the HWC facility to higher centers will be followed up in the community by the team of an accredited social health activist (ASHA), multipurpose health worker (MPW) and CHO. This will help in tracking each individual patient and ensuring compliance with the treatment prescribed. Provision of dispensing medicines at HWCs to the patients initiated on treatment at a referral facility has been made. On the other hand, continuum of care along the life cycle is also envisaged at the HWCs through providing services required right from conception like antenatal care till old age i.e., palliative care. $^{6}$

\section{Health promotion and disease prevention}

Health promotion and disease prevention activities like yoga are inbuilt in this system for the first time. Proposed HWC-PHC would have a dedicated yoga training center and the yoga instructor is supposed to train the community. ${ }^{6}$

\section{Extra manpower}

Inadequate manpower at the existing health facilities has been one of the major roadblocks in making peripheral health facilities optimally functional. With the introduction of additional manpower in form of $\mathrm{CHO}$ or mid level health providers at the HWC-SHC level is a much-needed welcome step. Not only this has helped in extending the package of services available to the population, this is to likely also help in improving the quality of services, monitoring and supervision of the grass root level workers and better data management and reporting at the HWCs. ${ }^{6}$

\section{Community participation to the next level}

In addition to the health promotion and disease prevention activities through the existing platforms like village health sanitation nutrition committee (VHSNC), Mahila Aarogya Samiti (MAS); under the PM-JAY (ABS) school children have been identified as the key torch bearer for the health promotion activities to carry the message forward not only to the present generation but also to the future generations as well. ${ }^{6}$

\section{STRENGTHS}

\section{Wider range of services}

Wider range of services including promotive, preventive, curative services (both clinical and diagnostic) - nearer to the community which takes HWC initiative closer to the 'comprehensive PHC. This will also decrease the OoP expenditure of the population, decrease avoidable patient load at the secondary and tertiary health care facilities and is likely to increase both the patient satisfaction and utilization of public health services in general.

\section{Two-way referrals}

Two-way referrals to ensure continuum of care so that there will be better management and follow up of the patients at appropriate health facilities and in the community itself in a health care system which is more responsive to the needs of community. This will work in two ways i.e., firstly increasing belief of the population in the public health system and secondly by increasing the contact of the health system with the population they serve.

\section{Additional trained human resource}

Additional trained human resource in terms of $\mathrm{CHO}$ to deliver clinical, managerial and public health functions. It is likely to result in better management and service delivery. Other expected benefits include better planning, timely reporting and that $\mathrm{s} / \mathrm{he}$ will be acting as resource person and providing supportive supervision to MPWs and ASHAs under the respective HWCs.

\section{Risk assessment of the whole empaneled population}

Risk assessment of the whole empaneled population within the HWCs and then planning and programming of 
prevention and management plan according to the requirements of the population. This likely to result in prevention of many chronic conditions. Also, screening will help in detection of common NCDs and selected cancers in early stages. This has potential to reduce the burden of patients at already congested secondary and tertiary care health facilities in the long run.

\section{The philosophy of team work}

The philosophy of team work in operationalizing HWCs is likely to be the biggest strength of HWC model of 'Comprehensive' primary health care delivery. This will provide a sense of ownership and personal responsibility to all the stakeholders be it the MPW, CHO or Medical officer in-charge at the PHCs. In addition, financial incentive linked with the performance for the team will nudge them to provide good quality services and work together efficiently.

\section{WEAKNESSES}

\section{Care or services at referral centers or facilities}

HWCs focus on providing comprehensive services at grassroot level. However, if the screened patients don't receive definitive diagnostic tests or if those diagnosed with conditions requiring management at higher facilities but the higher facilities are found wanting in providing such services; people will lose confidence in public health system. The already congested secondary and tertiary care facilities may become even more overburdened. ${ }^{14,16}$ As of now there is no comprehensive plan in public domain to improve or strengthen the public health facilities at the top of the health care pyramid i.e. secondary and tertiary care facilities. If this is not done, the HWCs initiative may become a failure after attaining a brief success for no fault of its own.

\section{OPPORTUNITIES}

\section{Opportunity to make a population-based health registry database}

The proposed population enumeration data to be collected and risk assessment of each individual to be done at each of the HWC can be collated after providing/ assigning individual ID to each member of the population. This will help in tracking morbidity and mortality pattern and health care utilization pattern in the population.

\section{Effective supervision of MPWs and ASHAs}

Since a new cadre of staff residing close to the community and stationed in HWC-SHC has been created, this can also be utilized for the improving supervision of ASHA and MPW activity at the field level. This will also aid in better implementation of national health programmes.

\section{Capacity building}

This program also provides opportunity to reorient and retrain health care providers at all levels to enhance their skill set to perform a wider range of functions effectively.

\section{To show political and administrative commitment through rapid up scaling}

Rapid upscaling will send an unambiguous message that the program is here to stay, and health care providers will need to upskill themselves at the earliest. This will also ensure people do not suffer in absence of services if they had HWC close to them, while piecemeal scaling is being done.

\section{To improve expenditure on public health care}

Public expenditure on health care provision is only about $1.18 \%$ of the gross domestic product (GDP) of the country. ${ }^{16}$ Recruitment of extra manpower and extra service component in the HWC will lead to increase in Public health expenditure. This opportunity can also be utilized to improve the public secondary and tertiary care health facilities in the country, which in turn strengthen HWC initiative.

\section{THREATS}

The following threats are perceived to the HWC based comprehensive primary care initiative in the country.

\section{Human resource}

According to the rural health statistics data around $40 \%$ of the posts of the auxiliary nurse midwife posts and $90 \%$ of the MPW; male posts are vacant. Building a new development model over the already poorly built substructure may lead to collapse of the whole structure. Similarly, in large proportion of PHCs in India there is no availability of the medical officers (MBBS). In such cases if consultation is required, to whom will the $\mathrm{CHO}$ or MPW contact? ${ }^{17}$

\section{Capacity}

Addition of services to the existing package of services at the HWC requires that medical officers at PHCs must be well versed with the updated management guidelines of all these conditions. Many of the medical officers will need training or refresher trainings to perform their role satisfactorily as a member of team in the scheme of things of the HWC initiative. Similarly, if rapid upscaling is to be done the initial requirement for appropriately trained CHOs will be huge. To achieve such numbers without compromising on quality also needs consideration of policy makers. 


\section{Conflicts between different cadre of health care providers}

CHOs will be in-charge of the HWC-SHC in the new scheme of things. They are supposed to supervise the activity of MPWs and ASHAs. But the new cadre coming in may be completely rejected by the workers who have been in-service for many years and have become used to working in a certain way. This could manifest as breakdown of communication between the team members, hostility towards the new cadre, noncooperation in service delivery or even in form of organized protest at different levels.

\section{Commodities}

Similar to human resource there is scarcity of the infrastructure and essential commodities at the ground level in many parts of the country. ${ }^{17}$ With introduction of the newer sets of services at the ground level, there will be requirement of newer set of drugs and logistics, which will be very challenging for the health system to deliver. Even if one-time delivery is done, it will require sustained effort, funding and supply chain management to ensure continued availability of logistics, drugs and other essential supplies.

\section{Continuum of care}

In the HWC concept of continuum of care the $\mathrm{CHO}$ is supposed to dispense medicines for various diseases in the HWC-SHC for continuing treatment started at a referral center in consultation with a Medical officer/ specialist. Here the main problem will be the mechanism through which medical officer/ specialist will be consulted? Will a telephonic consultation be considered good enough? ${ }^{18}$ Issue of poor network/ internet connectivity still exist in many parts of the country. Another tricky situation which will require clear guidelines is one where a patient walk in with a private practitioners prescription and asks the $\mathrm{CHO}$ to dispense medicine What CHO is supposed to do in such situation? Also ensuring follow up in community by ASHA or MPW will remain a big challenge given the existing workload of ASHA. Thus, continuum of care is going to be the most challenging aspect threatening the success of the whole model in the opinion of the authors of this paper.

\section{Role confusion}

In the proposed system many of the CHOs expected role/ activities are similar to the activities of the MPW. This will create a state of confusion regarding roles and responsibilities among health care providers. This may result in conflict between the CHOs and MPWs.

\section{Political change in the ruling dispension}

As priorities and mechanism to deliver on the priorities often change with change in the policymakers at the top, a new ruling dispension with new ideas and priorities may not find the HWC initiative attractive. Resultant cut in funding or political commitment will certainly weaken the initiative significantly if not kill it out rightly.

\section{CONCLUSION}

The HWC initiative to deliver a 'comprehensive' primary care services to predominantly rural population of India has envisaged to widened the package of services, provide continuum of care and provide an additional health care provider at the peripheral level. These are very relevant changes long overdue in the primary health care system in the country. We have already discussed the strengths, weaknesses, opportunities and threats to this initiative. However, this initiative does not alter the basic three tired structure of the pre-existing health system. This initiative strengthens the lowest rung of the preexisting system and envisages addressing the changing health priorities but the vulnerabilities and weaknesses of older system are likely to persist and threaten its success unless specifically addressed with strong commitment at the top.

\section{Funding: No funding sources \\ Conflict of interest: None declared \\ Ethical approval: Not required}

\section{REFERENCES}

1. Institute of Health Metrics and Evaluation, GBD Compare, Available at: https://vizhub.healthdata. org/gbd-compare/. Accessed on 24 July 2019.

2. National Health Accounts of India, National Health Accounts Technical Secretariat, National Health Resource Centre, Ministry of Health and Family Welfare, Govt. of India, Available at: https://mohfw. gov.in/sites/default/files/National\%20Health\%20Ac counts\%20Estimates\%20Report\%202014-15.pdf.

Accessed on 24 July 2019.

3. Household Health Expenditures in India (2013-14), National Health Accounts Technical Secretariat, National Health Resource Centre, Ministry of Health and Family Welfare, Govt. of India, Available at: https://mohfw.gov.in/sites/default/files/ 38300411751489562625.pdf. Accessed on 24 July 2019.

4. National Health Policy, 2017, Ministry of Health and Family Welfare, Government of India, Available at: https://mohfw.gov.in/sites/default/files/ 9147562941489753121.pdf. Accessed on 24 July 2019.

5. Declaration of Primary Healthcare, Astana, World Health Organization, Available at: https://www. who.int/primary-health/conference-phc/declaration. Accessed on 24 July 2019.

6. Ayushman Bharat Comprehensive Primary Health Care through Health and Wellness Centres, Operational Guidelines, National Health System Resource Centre Available at: http://nhsrcindia. 
org/sites/default/files/Operational\%20Guidelines $\% 2$ 0For $\% 20$ Comprehensive $\% 20$ Primary $\% 20$ Health $\% 2$ 0Care\%20through\%20Health\%20and\%20Wellness \%20Centers.pdf. Accessed on 24 July 2019.

7. Operational Guidelines on Ayushman Bharat National Health Protection Scheme (AB-NHPM), Ministry of Health and Family Welfare, Govt. of India, Available at: https://ayushmanbharatharyana.in/assets/pdfs/AB-NHPM\%20 Operational\%20Guidelines\%20June\%202018.pdf. Accessed on 24 July 2019.

8. Press Bureau of India, Government of India, Health and Wellness centers under Ayushman Bharat, Available at: http://pib.nic.in/newsite/PrintRelease. aspx?relid=188246. Accessed on 24 July 2019.

9. Indian Public Health Standards (IPHS) Guidelines for Sub-center (Revised 2012), Directorate General of Health Services, Ministry of Health and Family Welfare, Govt. of India, Available at: https://nhm. gov.in/images/pdf/guidelines/iphs/iphs-revisedguidlines-2012/sub-centers.pdf. Accessed on 24 July 2019.

10. Indian Public Health Standards (IPHS) Guidelines for Primary Health Centre (Revised 2012), Directorate General of Health Services, Ministry of Health and Family Welfare, Govt. of India Available at: https://nhm.gov.in/images/pdf/ guidelines/iphs/iphs-revised-guidlines-2012/primayhealth-centres.pdf. Accessed on 24 July 2019.

11. Indian Public Health Standards (IPHS) Guidelines for Community Health Centres (Revised 2012), Directorate General of Health Services, Ministry of Health and Family Welfare, Govt. of India, Available at: https://nhm.gov.in/images/pdf/ guidelines/iphs/iphs-revised-guidlines-2012/ community-health-centres.pdf. Accessed on 24 July 2019.

12. Indian Public Health Standards (IPHS) Guidelines for Sub-District/ Sub-Divisional Hospitals (Revised 2012), Directorate General of Health Services, Ministry of Health and Family Welfare, Govt. of India, Available at: https://nhm.gov.in/images/ pdf/guidelines/iphs/iphs-revised-guidlines-2012/sub- district-sub-divisional-hospital.pdf. Accessed on 24 July 2019.

13. Gupta AK, Talati S, Bhattacharya S, Singh A, Health System Strengthening- Focusing on Referrals: An analysis from India. JOJ Nurse Health Care. 2017;2(4).

14. Report of the Working group on tertiary care institutions for tertiary care centres, Available at: http://planningcommission.nic.in/aboutus/committee /wrkgrp12/health/WG_2tertiary.pdf. Accessed on 29 July 2019.

15. Prevention Screening and control of common non communicable diseases: Hypertension, Diabetes and Common cancers, National Health Mission, Govt. of India, Available at: https://mohfw.gov.in/sites/ default/files/Operational\%20Guidelines $\% 20 \mathrm{on} \% 20 \mathrm{P}$ revention $\% 2 \mathrm{C} \% 20$ Screening $\% 20$ and $\% 20$ Control $\% 2$ 0of\%20Common\%20NCDs.pdf. Accessed on 29 July 2019.

16. National Health Accounts Estimate for India, National Health Accounts Technical Secretariat National Health Systems Resource Centre Ministry of Health \& Family Welfare, Government of India, Available at: https://mohfw.gov.in/sites/default/ files/NHA_Estimates_Report_2015-16.pdf.

Accessed on 3 August 2019.

17. Rural Health Statistics 2017-18, Ministry of Health and Family Welfare, Govt. of India, Available at: https://nrhm-mis.nic.in/pages/rhs2018.aspx?root folder $=\% 2$ frural $\% 20$ health $\% 20$ statistics $\% 2 \mathrm{f} \% 28 \mathrm{a} 29$ $\% 20 \mathrm{rhs} \% 20-\% 202018 \&$ folderctid=0x01 200057278FD1EC909F429B03E86C7A7C3F31\&V iew $=\% 7 B 09 D D D 7 F 4-80 D 0-42 E 3-8969-$ 2307C0D97DDB\%7D. Accessed on 29 July 2019.

18. Ateriya N, Saraf A, Meshram VP, Setia P, Telemedicine and Virtual consultation: The Indian perspective. Natl Med J India. 2018;31:215-8.

Cite this article as: Solanki HK, Rath RS, Silan V, Singh SV. Health and wellness centers: a paradigm shift in health care system of India?. Int J Community Med Public Health 2020;7:799-805. 